\title{
Global Assimilation of Loon Stratospheric Balloon Observations
}

Lawrence Coy ${ }^{1}$ Mark Schoeberl ${ }^{2}$ Steven Pawson ${ }^{1}$ Salvatore Candido ${ }^{3}$ and Robert W. Carver ${ }^{3}$

'NASA Goddard Space Flight Center, Greenbelt, MD, USA: 2Science and Technology Corp, Columbia, MD, USA: LLoon, Mountain View, CA, USA

\section{The Problem}

Verification of global data assimilation system (DAS) output fields by independent observations insures the quality of these products for scientific studies and can highlight the need for additional observations to improve the quality. This is especially important for middle atmosphere winds where there are few "in situ" observations available to constrain the DAS. Here we use constant pressure balloon derived winds to evaluate the lower stratospheric winds in the NASA GEOS DAS.

\section{Loon Balloons}

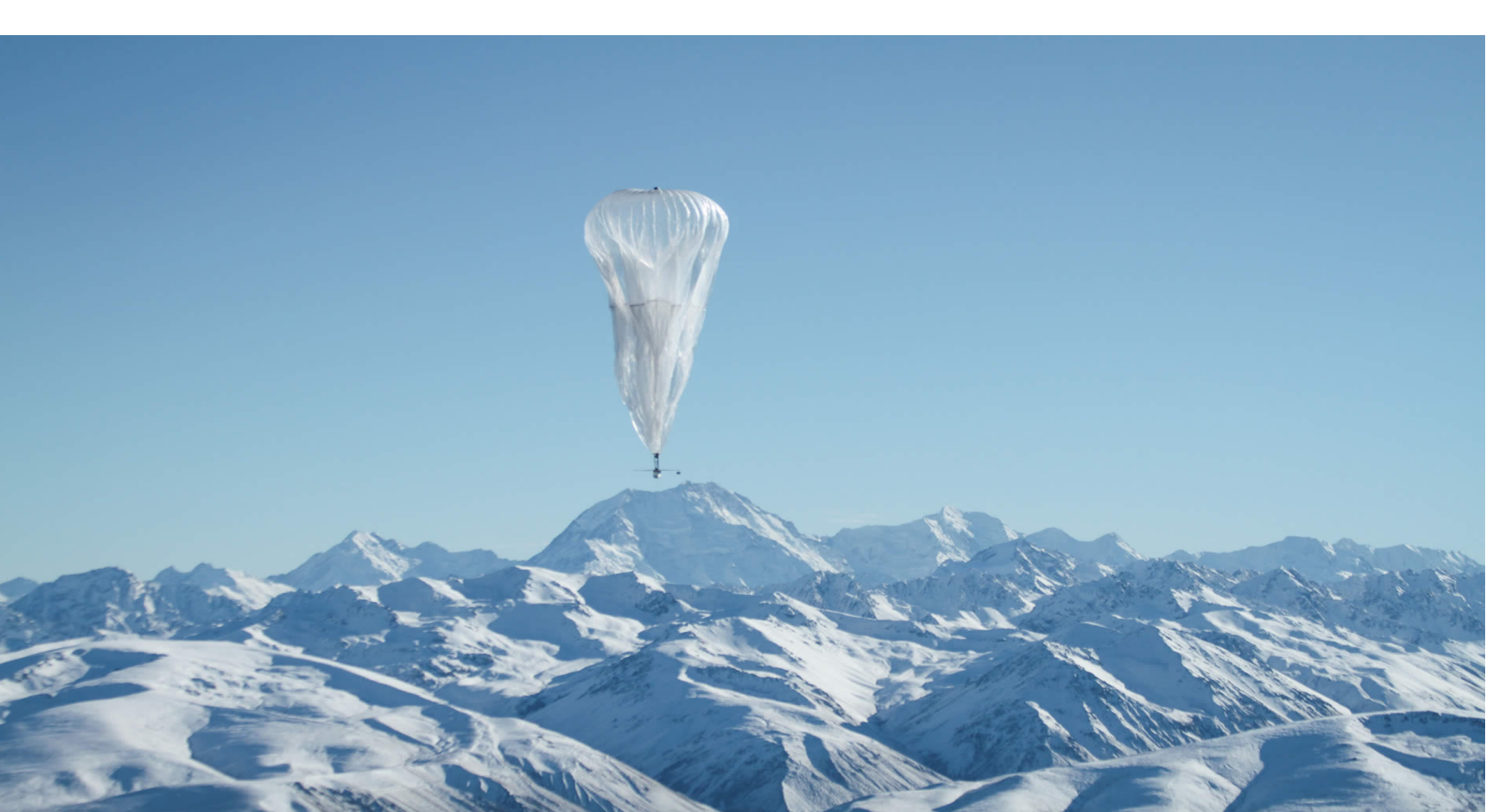

Goal: launch and maintain a fleet of balloons to provide Internet coverage to users on the ground.

Status: over 25 million $\mathrm{km}$ of test flights

Flight Duration: up to 190 days in the stratosphere.

Winds: Derived from Loon Balloon GPS https://loon.co/ determined locations. since the project began.

\section{Forecast Improvement (o-f) RMS Summary}

Assimilated Loon Balloon Winds All Loon Observations $\quad \begin{aligned} & \text { Control and Loon Obs show } \\ & \text { large }(>10 \mathrm{~m} / \mathrm{s}) \text { differences }\end{aligned}$ greatly improves the tropical background forecast

Note: o-f denotes the difference between the observation and the short background forecas

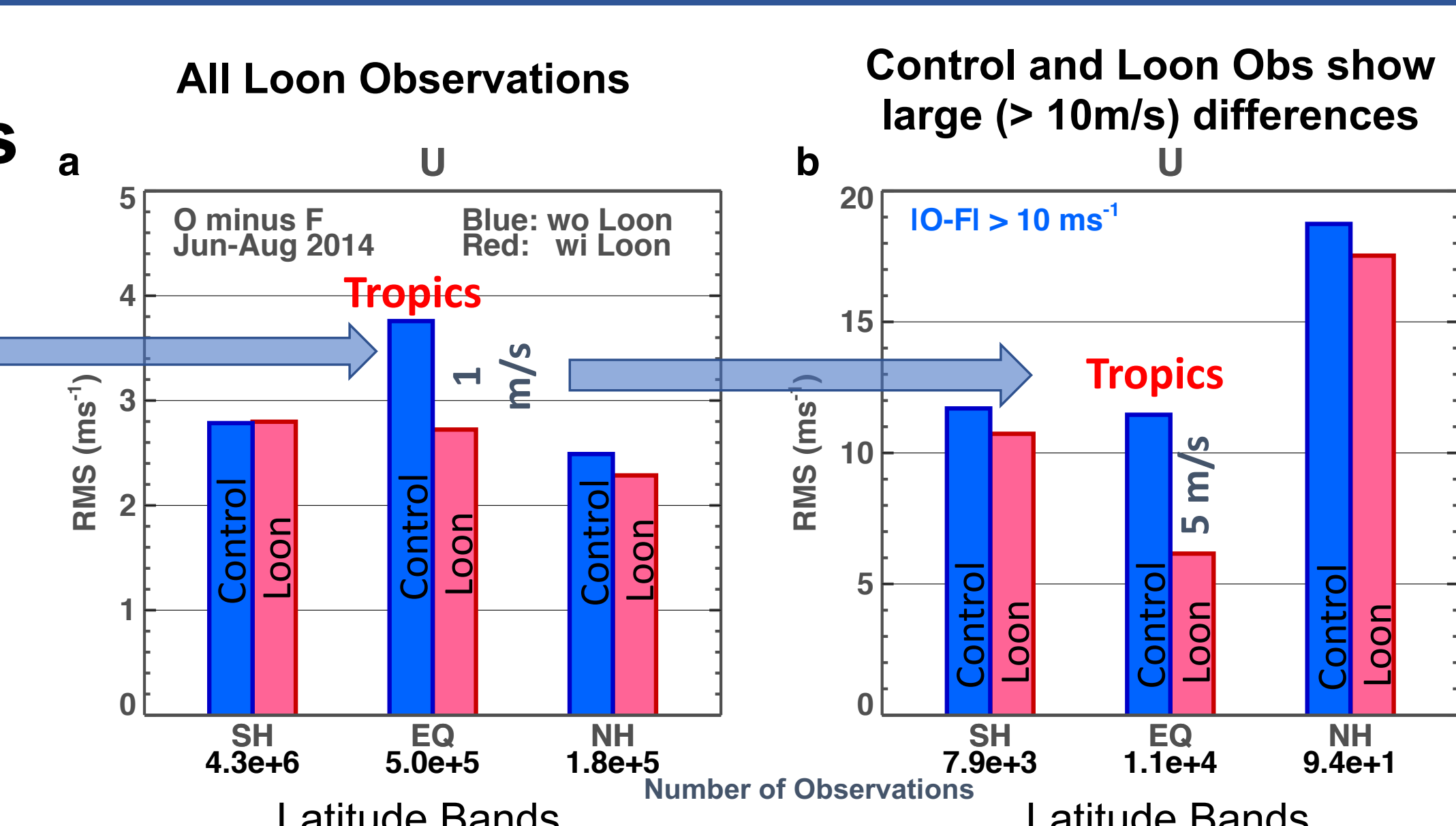

Analysis Improvement (o-a) RMS Example

Analysis winds interpolated by the DAS in space and time to the Loon position

Note: o-a denotes the difference between the observation and the DAS analysis

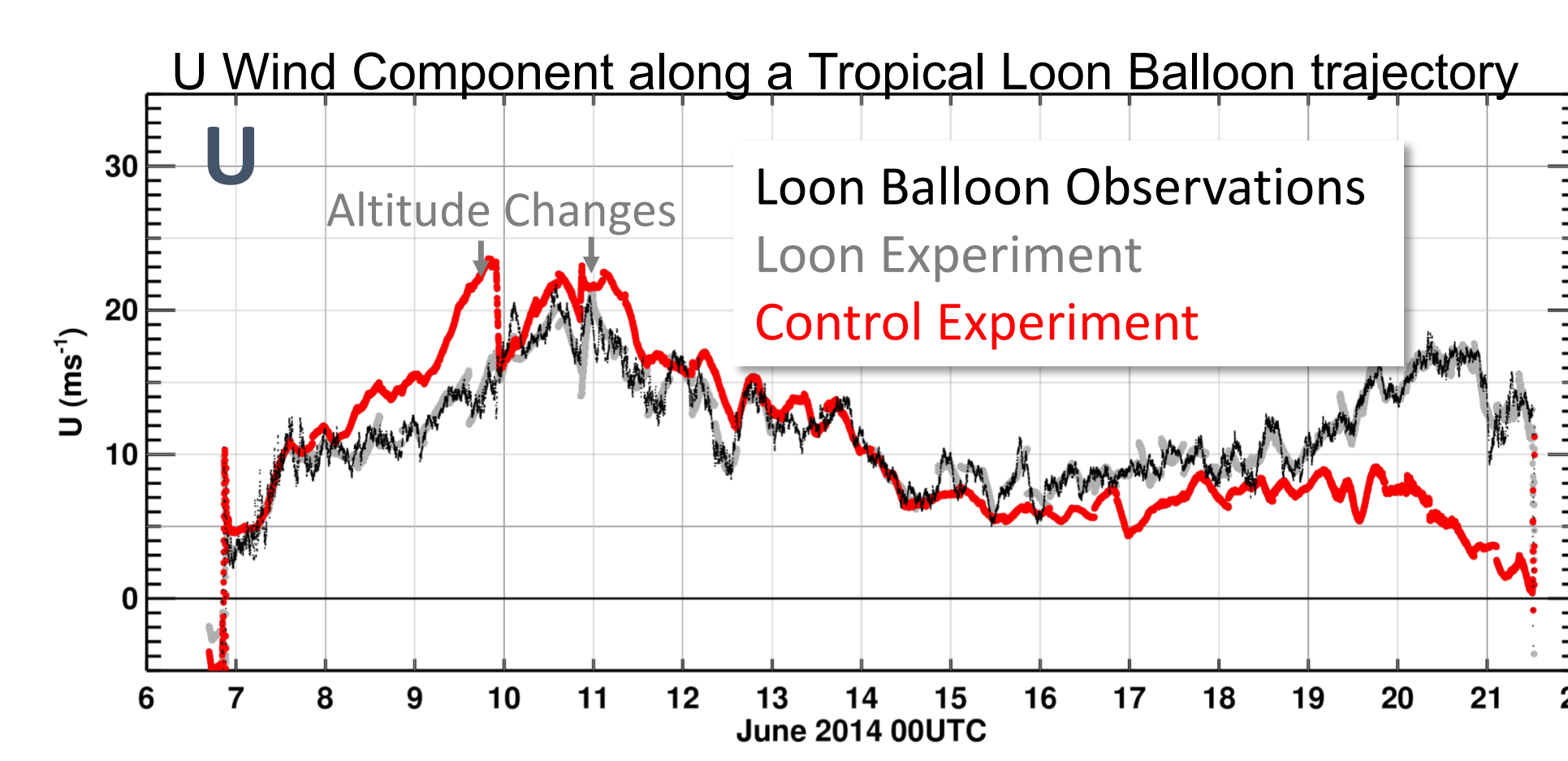

Large differences occur between the Control Experiment Analysis and Loon Observations that are corrected in the of each other.)

\section{Analysis Differences (RMS) August 2014}

\section{Methodology}

NASA GMAO MERRA-2 Data Assimilation System

Two Experiments:

1. Control Experiment (assimilation of standard observation set)

2. Loon Experiment (assimilation of Loon balloon

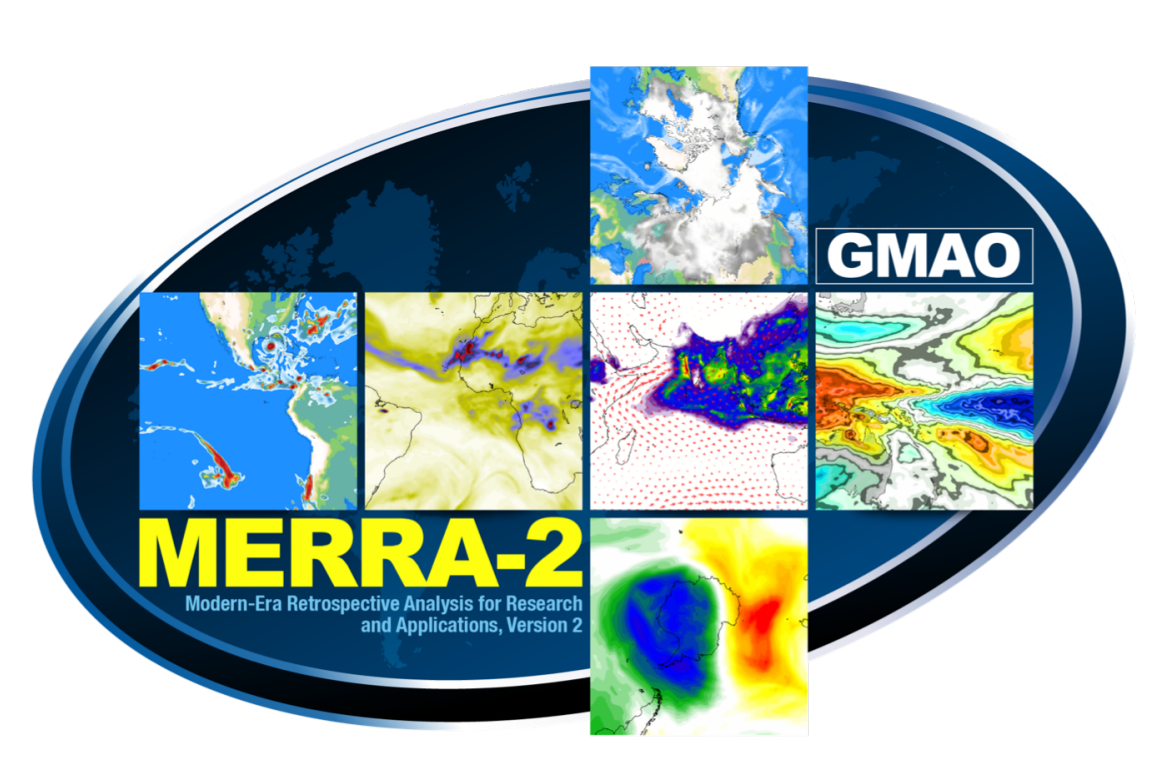
derived winds + standard observation set)

Test Time Period: June-August 2014 (large number of Southern Hemisphere Loon Balloons)

\section{Loon Balloon Distribution (June-August 2014)}

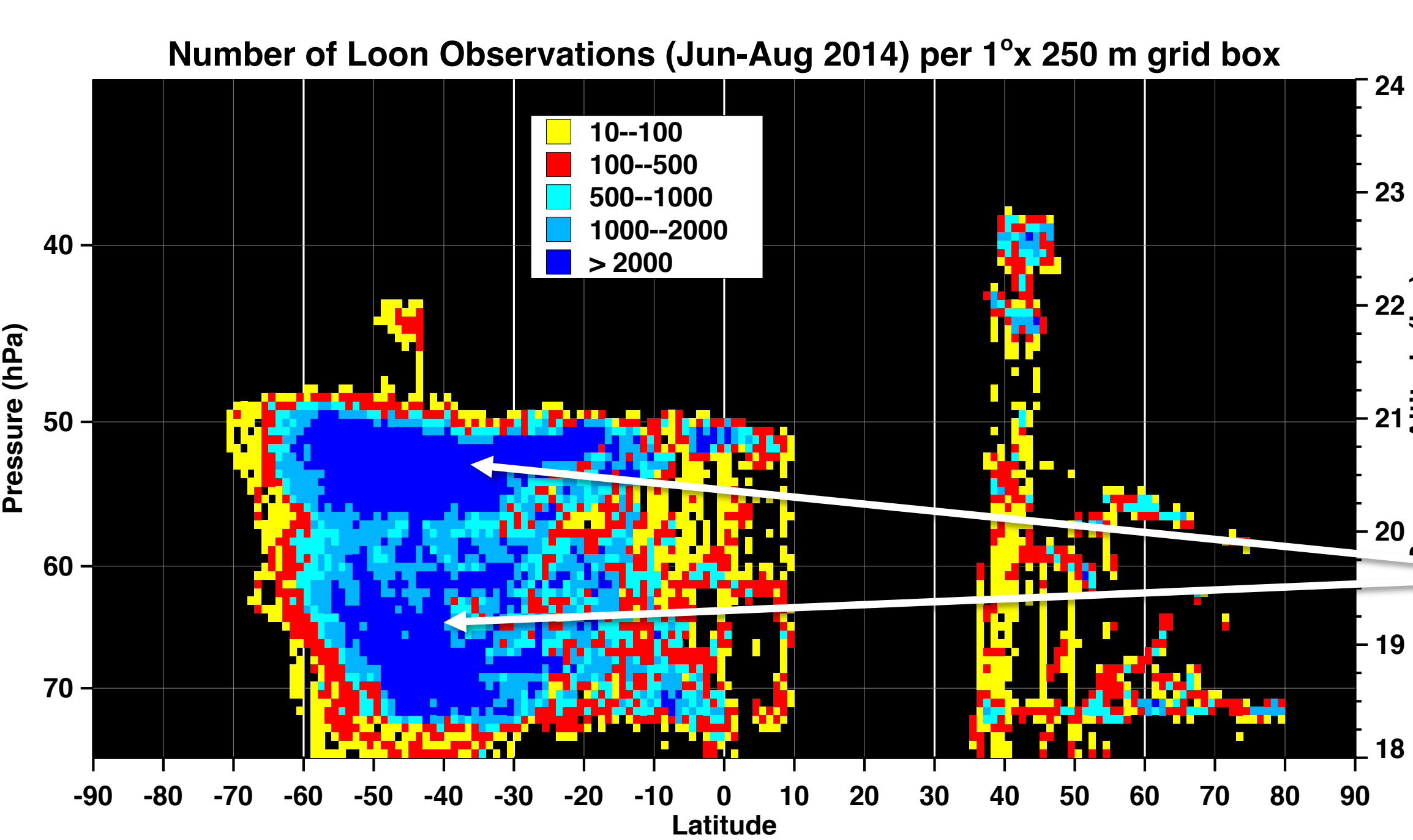

Southern Hemisphere Loon Balloons 70-50 hPa $(18-21 \mathrm{Km})$ Altitude $60^{\circ} \mathrm{S}$ to $10^{\circ} \mathrm{N}$ Latitude

Balloon Altitudes are adjusted while in flight

\section{Examples of Loon Balloon Coverage}

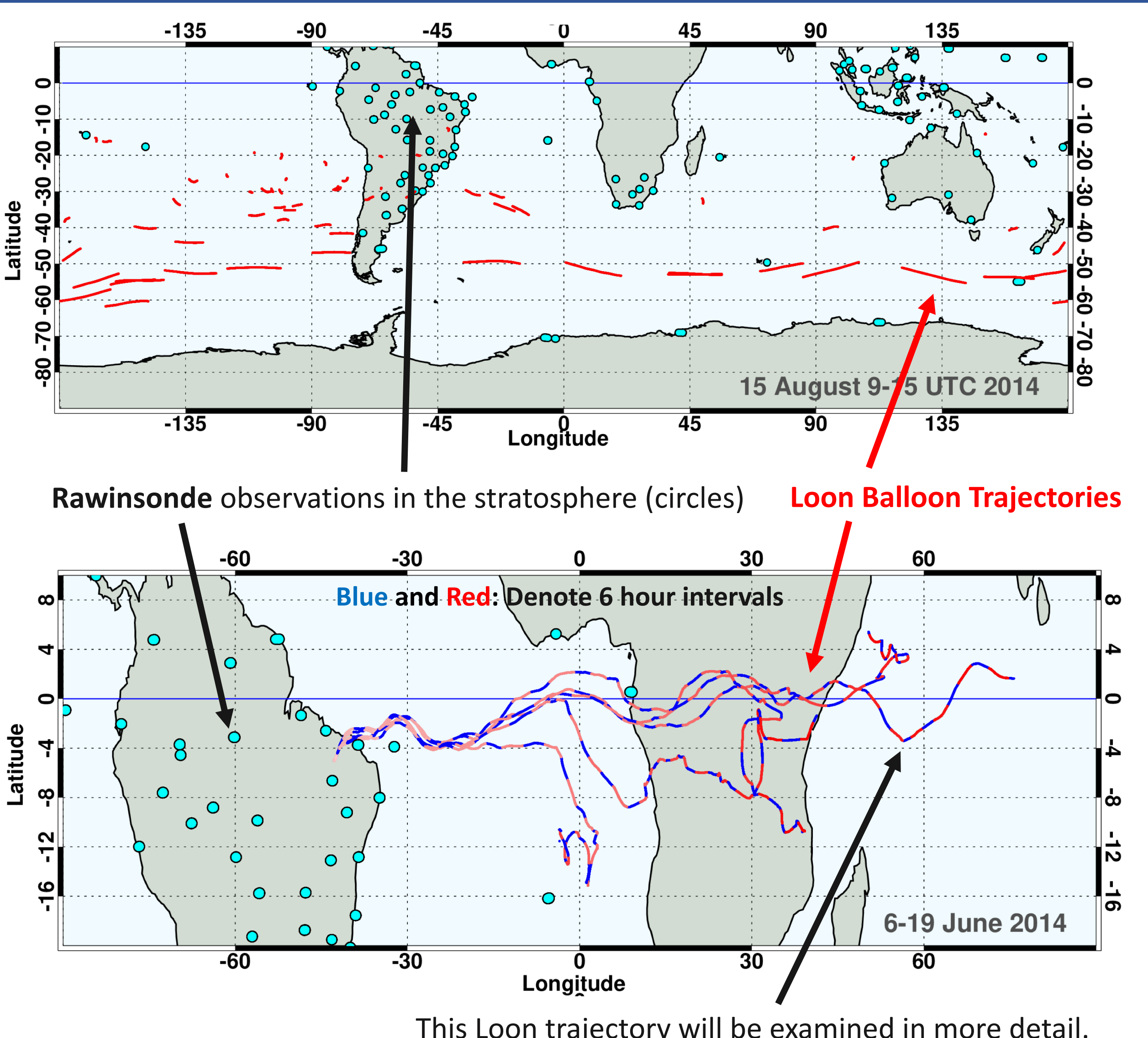

6-Hour Assimilation System Data Window Loon balloons can fill in wind observations over the oceans.

\section{Days Tropica} Coverage

Tropical observations provided some of the largest DAS adjustments when assimilating the Loon winds.
Control and Loon Balloon differences found mainly at Loon Balloon Altitudes

Evidence of some influence extending into the troposphere, below the Loon Balloon altitude.

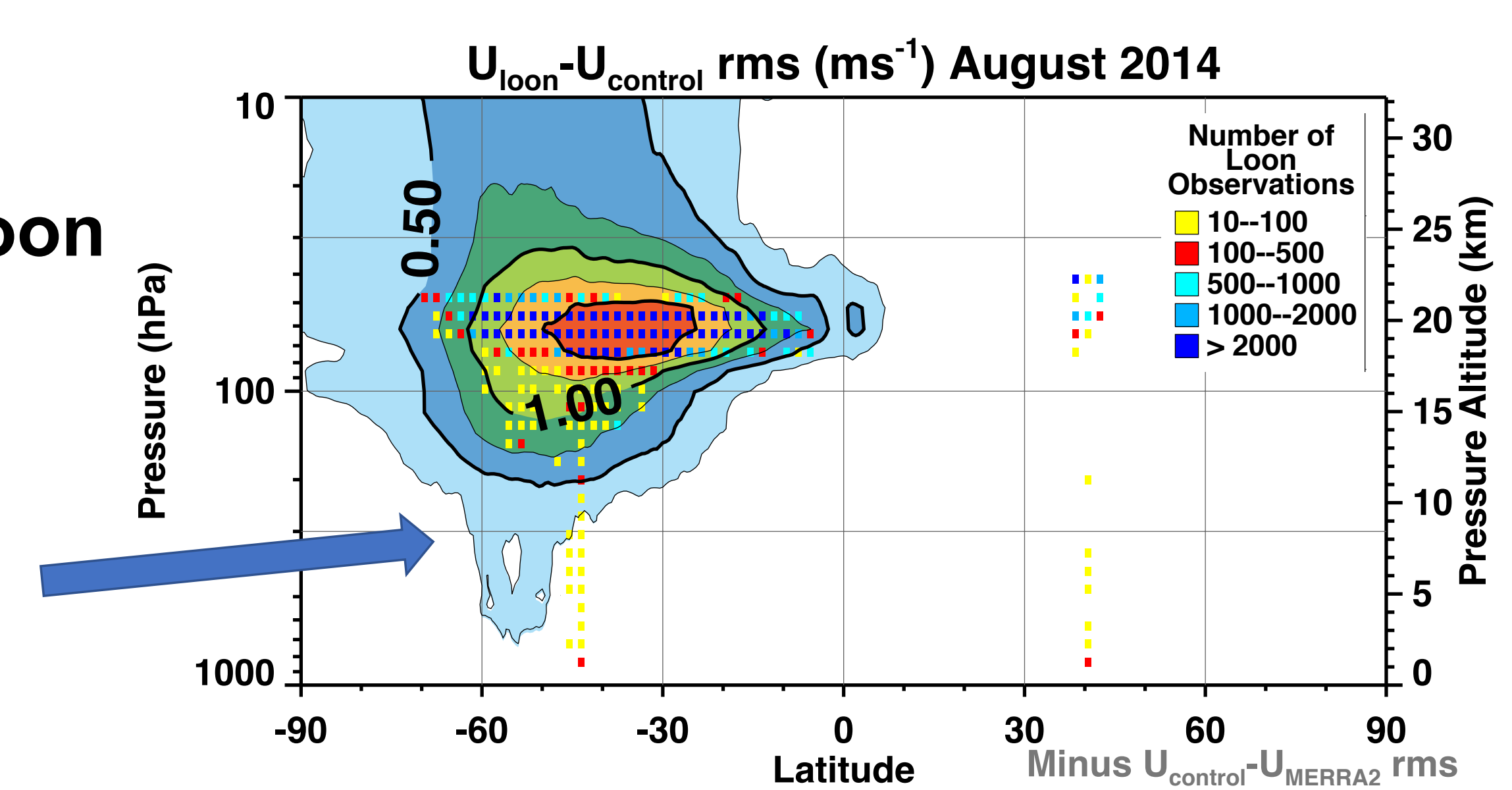

\section{Additional Test Time Period (June-August 2016)}

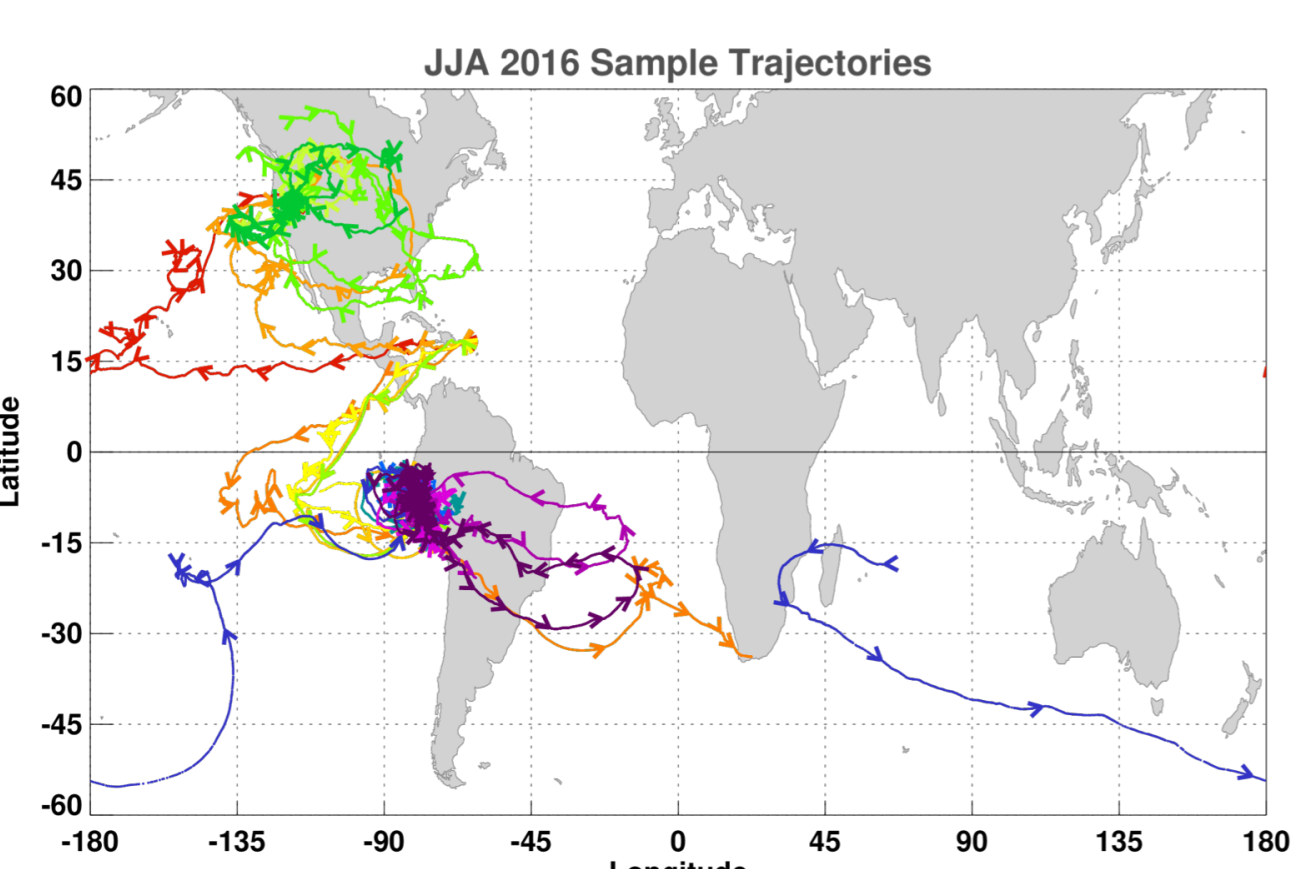

Sample Trajectories ( 100-70 hPa Altitude Range) Western Hemisphere Concentration

Confirmation of 2014 Results O-F RMS

Improvements at all latitudes, more significant improvement in tropics

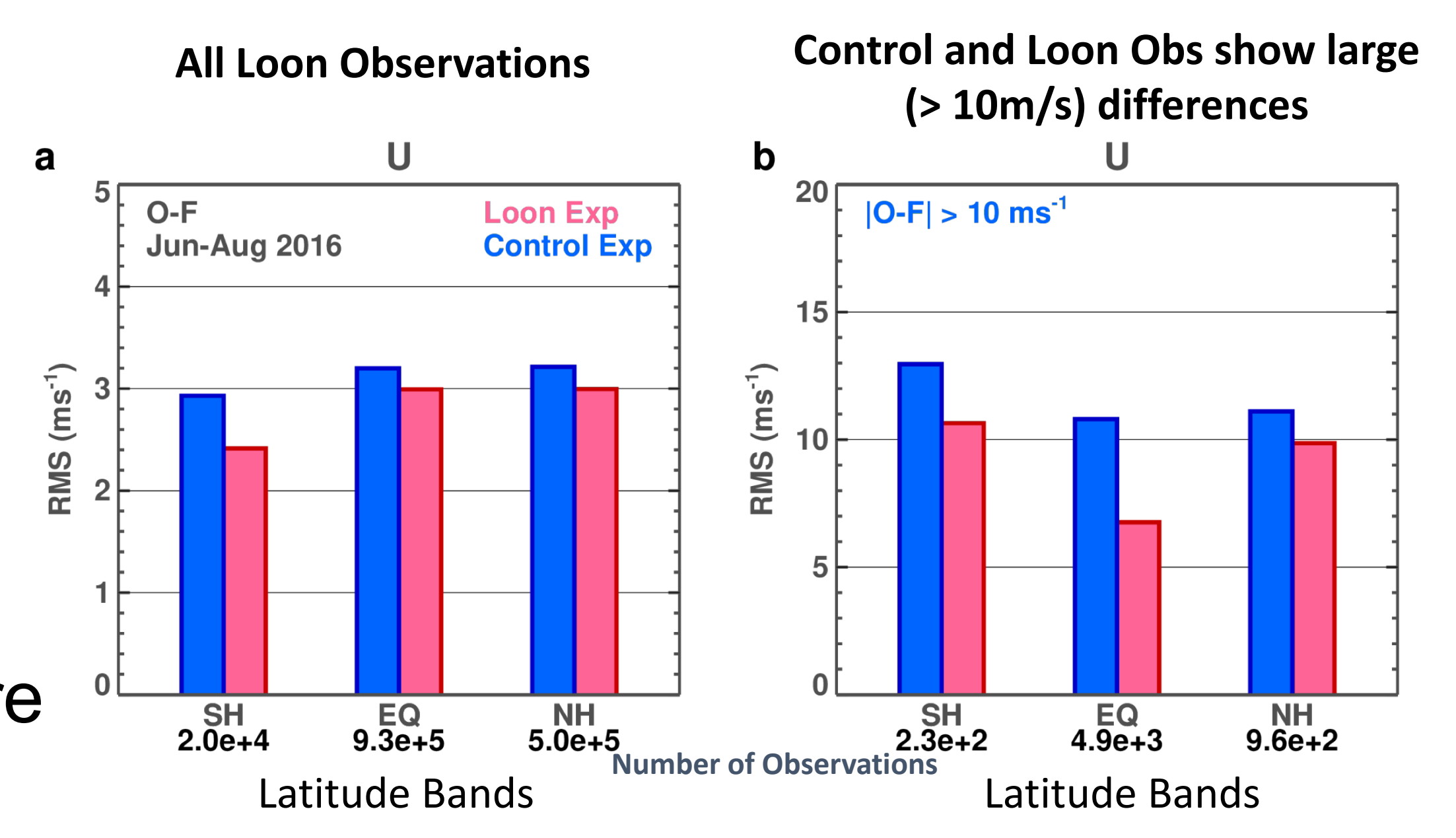

\section{Conclusions}

1. Additional wind observations can improve data assimilation products in the lower stratosphere, especially in the tropics

2. Current tropical wind analyses in the lower stratosphere can have errors larger than $10 \mathrm{~ms}^{-1}$

3. Some of the stratospheric wind analysis improvement may be accompanied by improvements in the upper troposphere wind analysis (further investigation is planned)

Coy, L, M. R. Schoeberl, S. Pawson, S. Candido, \& R. Carver, 2018, Global assimilation of $X$ Project Loon stratospheric balloon observations, Submitted to J. Geophys. Res. 